\title{
Marco teórico para el estudio de las experiencias religiosas extraordinariass
}

\author{
ESTHER MIQUEL
}

RESUMEN: La antropología, la psicología y la neurología han llegado conjuntamente a la conclusión de que la capacidad de acceder a ciertos tipos de experiencias no ordinarias reflejadas en testimonios procedentes de culturas y religiones tradicionales es una potencialidad natural de nuestra especie. Este estudio propone un marco conceptual que permite hablar coherentemente de estas experiencias, así como de algunos de los fenómenos cognitivos y sociales que son capaces de generar.

ABSTRAC: Anthropological, psychological and neurological studies concur on the conclusion that the capacity to have certain types of non-ordinary experiences, suggested by many traditional and religious testimonies, is a natural aptitude of our species. In this paper I propose a conceptual framework that allows us to discuss in a coherent way about such experiences and some cognitive and social phenomena they are likely to generate.

\section{Introducción}

El presente estudio quiere proponer un marco conceptual coherente que posibilite hablar con rigor de lo que en el lenguaje corriente entendemos por "experiencias religiosas extraordinarias". Aunque parte de nociones familiares en la tradición cultural del occidente cristiano, mi propuesta quiere ser aconfesional y, por tanto, útil tanto para quienes identifican la causa última de dichas experiencias en términos de una fe religiosa, como para quienes mantienen su reflexión en el ámbito de las perspectivas filosóficas o científicas. 


\section{Definiciones y conceptos}

En este escrito, el concepto de "experiencia” abarcará todo aquello que acaece al sujeto humano y tiene consecuencias en su vida consciente. Esta definición incluye experiencias inconscientes y subconscientes siempre y cuando produzcan efectos en la conciencia, aunque sea de forma indirecta, con la ayuda de alguna técnica psicológica o tratamiento psicoanalítico. Permite, por ejemplo, hablar de la experiencia de un sueño, en tanto en cuanto es posteriormente recordado, así como de la experiencia de sucesos vividos por el organismo de forma inconsciente o automática pero que en un momento determinado afloran total o parcialmente a la conciencia ${ }^{1}$.

Teniendo en cuenta la devastadora crítica que la filosofía occidental ha hecho a la idea de "realidad en sí", y con el fin, también, de establecer un marco teórico capaz de reconocer la variedad de interpretaciones que las distintas culturas dan a muchos contenidos de la experiencia, adoptaré en todo lo que sigue una concepción constructivista de la reali$\mathrm{dad}^{2}$. De acuerdo con esta concepción, lo "real" es lo que, en cada momento, el sujeto considera origen, fundamento o causa de su experiencia. La realidad es, pues, aquello en lo que el sujeto supone está anclada su experiencia.

La antropología, la psicología y la neurología apoyan, desde distintas perspectivas, esta definición de lo real y señalan los distintos niveles en los que la construcción de la realidad se hace patente en sus respectivas investigaciones ${ }^{3}$. Así, muchos neurólogos conciben el mundo sensible en el que el sujeto humano se considera inmerso, como una simulación. Dicha simulación, que de forma espontánea identificamos ingenuamente con la realidad en sí, se originaría en la interacción entre el organismo (especial-

\footnotetext{
${ }^{1}$ Metzinger distingue entre la conciencia fenoménica, que es siempre presente, y lo mental, que es toda aquella información poseída de algún modo por el organismo y que puede convertirse en conciencia fenoménica: MetZinger, T., Being no one. The self-model theory of subjectivity, The MIT Press, Cambridge MA - London 2003, pp. 15-31.

2 "Constructivism is a philosophical alternative to logical positivism, in which reality is considered to be created rather than apprehended and understood": KoKOsZKA, A., States of consciousness. Models for psychology and psychotherapy, Springer, New York 2007 pp. 32-33.

3 Para una aproximación constructivista a la conciencia desde el punto de vista de una filosofía de la mente que tiene en cuenta la neurología, ver: METZINGER, The ego tunnel. The science of the mind and the myth of the self, Basic Books, New York 2009.
} 
mente el sistema nervioso) y un entorno físico del que, por lo demás, sólo tenemos un conocimiento científico parcial e indirecto ${ }^{4}$.

La psicología cognitiva estudia desde hace tiempo los procesos constructivos, casi siempre preconscientes, que operan en la percepción, en la memoria y en la formación de imágenes y conceptos ${ }^{5}$.

La antropología, por su parte, descubre todos los días nuevas evidencias de la influencia que la socialización y el aprendizaje cultural ejercen en la concepción que los individuos tienen del mundo y de la naturaleza de las cosas ${ }^{6}$.

Nótese que esta definición no exige que lo real sea perceptible. Un científico, por ejemplo, puede afirmar la realidad de una partícula elemental en base a un modelo matemático o a experimentos indirectos. Por otra parte, esta definición nos ayuda a caer en la cuenta de que ni siquiera los llamados objetos sensibles, como las piedra o los árboles, se dan como objetos unitarios a nuestra sensibilidad, sino que son construidos por nuestro sistema cognitivo a partir de numerosas y variadas experiencias parciales a las que atribuimos una misma causa (imágenes visuales, táctiles, quinestésicas ... recuerdos, conocimientos aprendidos de nuestros mayores etc.).

La noción constructivista de lo real que aquí propongo acomoda sin dificultad la idea de que hay distintos tipos de realidades correspondientes a distintos tipos de experiencias. Esta idea, que choca con el reduccionismo materialista de la cultura popular científica de nuestros días, está sin embargo en la base de las ontologías religiosas tradicionales y es aceptada sin problemas por la visión del mundo de muchos grupos culturales. En la mayoría de estas ontologías y visiones del mundo tradicionales, las imágenes oníricas de ciertos personajes pueden ser coherentemente entendidos como el efecto de entidades reales (antepasados, dioses, espíritus) que quieren comunicarse con las personas a través del sueño. El sujeto que ha soñado distingue perfectamente entre su experiencia onírica y su experiencia despierta, pero en vez de reducir la primera al efecto de procesos neuronales o psicológicos, le atribuye una causa original, perteneciente a una realidad distinta de la de la vida cotidiana. Esta manera

\footnotetext{
${ }^{4}$ El conocimiento científico es también un conocimiento mediado por modelos, por teorías: MetZINGER, The ego tunnel, p. 18.

5 Fauconnier, G. - TUrner, M., The way we think. Conceptual blending and the mind's hidden complexities, Basic Books, New York 2002.

6 Berger, P. - Luckmann, T., The social construction of reality. A treatise in the Sociology of Knowledge, Doubleday, New York - London 1966.
} 
de interpretar los sueños difiere de la propia del reduccionismo científico, pero no es intrínsecamente contradictoria ${ }^{7}$.

La posibilidad de tener en cuenta discursos filosóficos y religiosos que reconocen distintos tipos de realidad nos permite, a su vez, entender y valorar las interpretaciones que muchas religiones y culturas tradicionales han dado a determinados tipos de experiencias extraordinarias.

Aunque el objetivo de este escrito es crear un marco teórico en el que poder hablar de forma consistente sobre las experiencias religiosas extraordinarias, las definiciones introducidas en este apartado y las reflexiones subsiguiente tendrán en consideración un solo rasgo de lo que usualmente calificamos con el adjetivo "religioso/a", a saber, el valor especial máximamente positivo que las entidades o fenómenos así calificados tienen a los ojos del sujeto o del grupo que los valora ${ }^{8}$.

El concepto "religión" es hoy muy discutido. Muchos autores incluso niegan la posibilidad de dar una definición comprehensiva y coherente de la enorme cantidad de fenómenos culturales a los que el lenguaje corriente o erudito ha aplicado este término. La estrategia conceptual de referirme sólo al aspecto valorativo de lo religioso me permite referirme en este escrito a todos los fenómenos que las definiciones tradicionales de religión incluyen, pero también a muchos otros cuya caracterización es discutida. Particularmente, a todos aquellos fenómenos de tipo espiritual, ético, estético o intelectual, que los sujetos en ellos implicados consideran sumamente valiosos, al margen de que sean reconocidos como tales por un grupo o una institución.

De acuerdo con esta aclaración, consideraré que las experiencias religiosas extraordinarias son simplemente una clase o tipo de experiencias extraordinarias máximamente valiosas.

La valoración de la experiencia depende, en primer lugar, del sujeto, pero la cultura del grupo humano en el que vive dicho sujeto juega también un papel crucial, ya que todas las personas interiorizamos durante la

7 CRAFFERT, P.F. The life of a Galilean shaman. Jesus of Nazareth in Anthropological-Historical perspective, Cascade Books, Eugene OR 2008, pp. 174-181.

8 TAVES, A., Religious experience reconsidered. A building-block approach, Princeton University Press, Princeton - Oxford 2009, considera la religión como la plena institucionalización de un itinerario de prácticas, formas de vida etc., que busca alcanzar algo singularizado como especial, generalmente un bien, una meta valiosa, pp.46-49. Esta caracterización permite incluir entidades negativas (demonios, espíritus impuros, dioses agresivos etc.) en el escenario religioso, pues en este caso la meta valiosa a alcanzar sería precisamente salvarse o protegerse de los efectos negativos producidos por tales entidades. 
infancia muchos de los valores de la sociedad en torno. Normalmente, las religiones, sea cual sea la manera como las definamos, tienen una gran influencia sobre la jerarquía de valores que determina el comportamiento y orientación vital de sus fieles. No es, por tanto, extraño que la valoración de una proporción importante de las experiencias extraordinarias documentadas por la historia y la antropología esté fundamentada en criterios de carácter religioso.

El carácter extraordinario (extra-ordinario) de una experiencia se define, simplemente, por oposición al carácter ordinario de las experiencias que constituyen la vida cotidiana (entiendo vida despierta). Lo ordinario es lo que se nos presenta como conocido o previsible tanto en su forma de aparecer como en su desarrollo, funcionamiento o comportamiento. Es aquello con lo que habitualmente contamos a la hora de organizar y programar nuestra actividad cotidiana. Las experiencias explicables son un caso particularmente claro de experiencias ordinarias, pues no sólo las concebimos como posibles, sino que además creemos saber la razón por la que son posibles. El caso extremo de lo ordinario es lo controlable, aquello que podemos hacer presente a voluntad mediante alguna técnica o método.

Evidentemente, las nociones opuestas de "experiencia ordinaria" y de "experiencia extraordinaria" son relativas y graduales. Son relativas porque la experiencia ordinaria de la vida cotidiana varía considerablemente de una cultura a otra e incluso de un individuo a otro. Son graduales porque para una misma cultura o un mismo individuo una experiencia puede tener más o menos elementos o rasgos no ordinarios.

Las experiencias más ordinarias son aquellas que configuran la vida cotidiana del sujeto, aquellas cuya ocurrencia no le sorprende porque las sabe controlar, porque ha aprendido a preverlas o porque las considera probables. Este tipo de experiencias son las más frecuentes en la vida despierta de cualquier persona, suelen tener una orientación predominantemente práctica, corroboran el conocimiento adquirido y contribuyen a desarrollarlo de forma coherente. Además son fácilmente compartidas entre los miembros del mismo grupo cultural, pues casi todos ellos las interpretan de forma parecida. Dado que todos los seres humanos tenemos organismos, sentidos y capacidades motoras similares, podemos suponer que existe un conjunto amplio de tipos básicos de experiencias ordinarias que son comunes a todos los individuos de nuestra especie.

Normalmente, el sujeto y su grupo de pertenencia asumen que las experiencias ordinarias están causadas u originadas por una realidad, a la que también llamaremos "ordinaria", y que constituye el mundo o escenario donde se desenvuelve su vida cotidiana. 
Las experiencias más extraordinarias son, por el contrario, aquellas que desconciertan totalmente al sujeto, quien, en un primer momento, ni siquiera es capaz de interpretarlas. Este tipo de experiencias cuestionan el conocimiento socialmente compartido y, dado que el lenguaje suele estar adaptado a ese conocimiento, son difíciles de expresar y comunicar. El carácter absolutamente extraño e imprevisible de estas experiencias impide que el sujeto pueda atribuirlas a causas u orígenes conocidos. Es por esto por lo que su mera ocurrencia le obliga a considerar la posibilidad de que la realidad ordinaria no explique la totalidad de lo que puede experimentar. Semejante consideración motiva con frecuencia la sospecha de que la causa u origen de la experiencia extraordinaria se halle en una realidad distinta de la realidad ordinaria o, al menos, en una dimensión de ésta que hasta entonces había permanecido oculta. A esta realidad o dimensión supuestamente irreducible a la realidad ordinara la calificaremos con el adjetivo "trascendente" 9 .

Aunque algunas filosofías y religiones defienden la existencia de lo trascendente apoyándose únicamente en la reflexión ${ }^{10}$, la mayoría de las religiones fundamentan este tipo de creencias en experiencias extraordinarias a las que atribuyen un carácter revelatorio. De acuerdo con ellas, en sus orígenes, la realidad trascendente se habría dado a conocer a sus fundadores través de este tipo de experiencias.

Así, por ejemplo, en el Cristianismo, el carácter divino o trascendente de Jesucristo Resucitado se fundamenta en las experiencias extraordinarias que sus seguidores afirmaron tener tras su muerte. La trascendencia del Dios de Israel se revela en sus numerosas intervenciones extraordinarias en la historia de los israelitas. Tanto en el pasado como en el presente, muchas personas consideran que la transcendencia del alma humana se revela en las experiencias extraordinarias a las que han podido acceder mediante la práctica de distintas disciplinas espirituales como la oración, la meditación, la contemplación etc.

\footnotetext{
9 'Trascendente' no significa necesariamente 'ultramundano'. Lo trascendente es un orden alternativo que se opone al de la vida cotidiana, pero que puede hacerlo desde el interior del mundo, manifestándose como el ser auténtico: RIIS, O. - WoOdHEAD, L., $A$ sociology of religious emotion, Oxford University Press, Oxford - New York 2010, p.70.

10 Por ejemplo, Platón y sus seguidores justifican la existencia del mundo de las ideas mediante argumentos meramente racionales. Esto no supone ningún obstáculo para que muchos platónicos, como por ejemplo, Plotino, creyeran haber tenido experiencias contemplativas de dicho mundo.
} 
Dado que la definición aquí propuesta de experiencia extraordinaria admite todos los grados imaginables -entre lo totalmente extraordinario y lo que sólo se diferencia de lo ordinario por algún elemento o aspecto mínimo- es obvio que no constituyen una categoría vacía. Los sueños, por ejemplo, son experiencias extraordinarias familiares para prácticamente todas las personas. La psiquiatría, por su parte, reconoce la ocurrencia de alucinaciones visuales y auditivas al menos en pacientes clasificados como esquizofrénicos. En otro ámbito, la experimentación con ciertas drogas por parte de personas con formación médica ha probado que, independientemente de cómo se las interprete, las experiencias extraordinarias son vivencias posibles para la especie humana ${ }^{11}$. Es posible discutir la posibilidad de algunos tipos de experiencia extraordinaria descritos en ciertas fuentes, es también posible aducir que muchos de los tipos descritos por la antropología, la historia de las religiones o los propios sujetos no están adecuadamente caracterizados, pero hoy día ya no es posible negar que la especie humana como tal tiene la capacidad de tener experiencias que contradicen la experiencia común básica de la vida despierta cotidiana $^{12}$.

\section{Variedades de experiencias extraordinarias}

Entre las experiencias extraordinarias no sólo descubrimos gradaciones sino también numerosas variedades. Desafortunadamente, los datos empíricos que tenemos acerca de este tipo de experiencias no se prestan fácilmente a la sistematización, pues la interpretación que el sujeto da de lo vivido es casi siempre parte inherente de la propia experiencia. Dado que la verbalización de lo vivido implica necesariamente un cierto grado de interpretación, la búsqueda de testimonios neutros (no sesgados) de experiencias extraordinarias es una empresa condenada al fracaso.

Como ya he señalado con anterioridad, las experiencias extraordinarias más frecuentes y espontáneas son los sueños. Son tan frecuentes

\footnotetext{
11 TART, C.T., On being stoned. A psychological study of Marijuana intoxication, Science and Behavior Books, Palo Alto CA 1971.

12 El filósofo Thomas Metzinger no sólo ha ofrecido testimonios en primera persona de experiencias fuera del cuerpo, sino que considera la capacidad humana para tener sueños y otros tipos de experiencias extraordinarias datos científicos útiles para construir modelos teóricos de la conciencia. Ver: Metzinger, The ego tunel, pp.; "Why are dreams interesting for philosophers? The example of minimal phenomenal selfhood, plus an agenda for future research", Frontiers in Psychology 4, art 746, 2013.
} 
que, hoy día, muchas personas los consideran experiencias ordinarias. No obstante, este juicio se apoya siempre en alguna teoría neurológica o psicológica que interpreta el sueño como resultado de ciertas operaciones complejas sobre componentes de la vida mental ordinaria. Es importante constatar aquí que, quienes consideran los sueños experiencias ordinarias deben darles una interpretación que los reduzca a componentes de una teoría sobre la mente o la conciencia. Es decir, también la ciencia impone sobre la experiencia onírica su propia interpretación. Por su parte, aquellos grupos humanos o culturas que interpretan los sueños como formas de contacto con realidades trascendentes no incurren en ninguna incoherencia, pues esta interpretación distingue perfectamente la realidad ordinaria de la vida despierta de la información sobre la realidad trascendente recibida a través del sueño.

Experiencias relativamente frecuentes, aunque no tanto como los sueños, son aquellas que la literatura científica denomina "experiencias fuera del cuerpo". Se caracterizan por que el sujeto siente dejar atrás su propio cuerpo, incorporándose a otro o quedando reducido a una entidad puramente mental. Estas experiencias, que están ampliamente documentadas, podrían ser el fundamento de lo que muchas culturas interpretan como viajes celestes o espirituales. Un caso paradigmático muy bien estudiado por la antropología son los viajes chamánicos. Un testimonio en primera persona de este tipo de experiencia en la historia de los orígenes cristianos es el recogido en la Segunda Carta a los Corintios (2 Cor 12,2-4) ${ }^{13}$.

Otra clase de experiencias extraordinarias que comparten algunos rasgos con las anteriores son las llamadas "experiencias de cercanía a la muerte". Son típicas en víctimas de accidentes graves o en pacientes agónicos que en el último momento logran recuperarse y sobrevivir. En ellas, el sujeto siente que se aleja de su propio cuerpo y entra en un ámbito de realidad distinto al de la vida cotidiana. Tenemos documentos antiguos y medievales que podrían reflejar experiencias de este tipo, aunque la componente interpretativa en clave religiosa suele ser tan preponderante que es difícil saber si responden a experiencias reales o no ${ }^{14}$.

13 Ver la interpretación de este texto en clave neurobiológica propuesto por SHANTZ, C. Paul in ecstasy. The neurobiology of the apostle's life and thought, Cambridge University Press, Cambridge - New York 2009.

14 Para una muestra de estudios sobre distintos tipos de experiencias extraordinarias testimoniadas por la antropología y tradiciones antiguas, ver: Collins, J.J. - FishBANE, M. (eds), Death, ecstasy and other wordly journeys, State University of New York Press, Albany NY 1995. 
Desde que se introdujo en la sociedad occidental el uso masivo de drogas psicodélicas y se pusieron de moda algunas prácticas meditativas inspiradas en las filosofías y religiones orientales, el número de testimonios aconfesionales sobre experiencias extraordinarias hechos por sujetos sanos se ha incrementado enormemente. Esto ha forzado a los neurólogos, psicólogos, antropólogos y filósofos a reconocer que la capacidad de tener experiencias extraordinarias similares, en algunos aspectos, a las testimoniadas por muchos textos religiosos antiguos o por individuos pertenecientes a culturas tradicionales no es siempre el resultado de patologías mentales, sino que es patrimonio de la especie humana como tal ${ }^{15}$.

De los tipos de experiencias que la literatura tradicional califica como éxtasis, encuentros con seres suprahumanos, posesiones espirituales, visiones, inspiraciones proféticas, viajes celestes, uniones o iluminaciones místicas etc., la investigación psicológica y neurológica actual centra su atención en aquellas características que más claramente contradicen la experiencia ordinaria básica compartida por todos los seres humanos: Alteraciones en la percepción del propio cuerpo, en el sentido del espacio o del tiempo, en la percepción visual o auditiva, en la capacidad de actuar sobre el entorno o de dirigir la atención, estados emocionales anormalmente intensos o difíciles de clasificar, selección y organización anómalas de datos perceptivos y de recuerdos ... Sin embargo, no podemos pretender que las nomenclaturas y clasificaciones tradicionales se correspondan exactamente con las científicas. Como he apuntado anteriormente, los contenidos y el marco interpretativo con el que el individuo accede a la experiencia es parte inseparable de ésta ${ }^{16}$. Por ejemplo, la experiencia tradicional de sentirse poseído por un espíritu nunca será equivalente a una experiencia con sensaciones semejantes pero vivida por un sujeto que no cree en la existencia de espíritus poseedores.

Hoy sabemos que algunas de las mencionadas alteraciones pueden inducirse o facilitarse mediante el uso de drogas, ciertas prácticas físicas y ascéticas como la danza rítmica, el control de la respiración, el ayuno, el aislamiento sensorial, la fijación prolongada de la atención, u otras técnicas

15 "It seems plausible that many reports about paranormal events and experiences are absolutely sincere reports about specific and highly realistic phenomenology - e.g., of moving outside one's body - which can now be explained in a more parsimonious manner": MetZinger, T. "Why are aout-of-body experiences interesting for philosophers? The theoretical relevance of OBE research", Cortex 45 (2009) 256-258, p. 257.

16 La cultura configura e incluso constriñe el tipo de experiencias que un sujeto puede vivir: MetZinger, The ego túnel, p. 28. 
más sofisticadas como la estimulación artificial de distintas partes del cerebro. Todo parece indicar que, desde muy antiguo, los seres humanos han buscado activamente algunos tipos de experiencias extraordinarias y han encontrado medios con los que favorecerlas o provocarlas. Este dato sugiere que algunas de estas experiencias o, al menos, la capacidad de acceder a ellas podrían tener ventajas biológica o culturalmente adaptativas.

Las reflexiones anteriores no deben hacernos creer que toda experiencia extraordinaria conlleva el tipo de alteraciones en la conciencia que la ciencia ha contrapuesto más claramente a la conciencia ordinaria básica común a toda la humanidad. Hay experiencias que son extraordinarias para un determinado sujeto o una determinada cultura pero podrían no serlo para otros sujetos y otras culturas. Es decir, experiencias que se oponen no a lo ordinario compartido por toda todos los seres humanos, sino sólo a lo que es ordinario para una persona o un grupo concreto. Es fácil entender que la erupción de un volcán en el territorio habitado por una población pre-científica que nunca antes hubiera visto un fenómeno semejante, no sólo produciría entre sus miembros una intensidad de terror inusitada, sino que haría tambalearse muchos de sus presupuestos culturales acerca de cómo es y cómo funciona el mundo. Este tipo de vivencia, que para la civilización científica occidental, pertenece al ámbito de la experiencia ordinaria, podría provocar en esa población cambios importantes en su forma de concebir el mundo o los dioses.

Aunque la ignorancia puede motivar que una experiencia sea vivida como extraordinaria, no es correcto identificar lo extraordinario con lo ignorado. Hay multitud de fenómenos cuyas causas profundas ignoramos pero cuya ocurrencia consideramos probable y, por tanto, no nos causan habitualmente extrañeza. Así, por ejemplo, podemos ignorar por completo los procesos por los que somos capaces de ver, pero el hecho de que contemos con la vista en nuestra vida diaria hace que la experiencia de ver nuestra habitación al despertar por la mañana no nos parezca en absoluto extraordinaria.

Lo extraordinario no sólo no debe ser comprensible; debe ser también inesperado, sorprendente, incongruente con los presupuestos que tenemos sobre lo que es posible en la vida ordinaria.

\section{Experiencia extraordinaria, control y comportamiento ritual}

En el apartado anterior he llamado la atención sobre el hecho de que en la mayoría de las culturas presentes e históricas hay personas que bus- 
can activamente métodos eficaces para tener ciertos tipos de experiencias extraordinarias.

Es necesario, sin embargo, constatar que un control completo de la forma y el contenido de una experiencia inicialmente considerada extraordinaria la convertiría en ordinaria. En el caso en que el sujeto pudiera elegir a voluntad el tipo de experiencia que desea tener, su contenido y el momento en que quiere tenerla, ésta entraría a formar parte de su conocimiento técnico, y por tanto, de su experiencia ordinaria. Así, si con un simulador pudiéramos acceder a voluntad a todas las sensaciones que tiene un chamán en sus viajes celestes o un yogui en estado de nirvana, es probable que, tras un periodo de habituación en el manejo del simulador, dejáramos de vivir semejantes experiencias como algo verdaderamente extraordinario. Ejemplos más familiares como las experiencias psicodélicas confirman esta idea. Sabemos, en efecto, que las experiencias descontroladas producidas por ciertas drogas como la marijuana en los neófitos pueden llegar a ser domeñadas gracias al conocimiento empírico obtenido mediante su uso reiterado.

Resumiendo, en la medida en que una experiencia inicialmente extraordinaria se vuelva más o menos controlable o previsible, dejará de ser plenamente extraordinaria. Este cambio sobreviene cuando el sujeto o el grupo en su conjunto descubren técnicas adecuadas para controlarlas o adquieren conocimientos capaces de predecir o explicar su ocurrencia.

El sujeto o grupo humano que llega a controlar totalmente algo que en un comienzo vivió como experiencia extraordinaria amplía el marco de su experiencia previsible y esto se traduce, en la mayoría de los casos, en una ampliación equivalente de su noción de realidad ordinaria. La razón de esta última ampliación es que la orientación práctica de nuestra vida cotidiana nos motiva a integrar en la realidad ordinaria todo cuanto identificamos como origen o causa de nuestra experiencia habitual.

La ampliación de la noción de realidad ordinaria es un fenómeno cultural bien conocido en la historia de la ciencia occidental. Entre las incorporaciones más sonadas a esta realidad están la de los "campos de fuerza" o la de las "ondas electromagnéticas". Ambos tipos de entidades tienen propiedades cuasi-mágicas, como la invisibilidad y la capacidad de actuar a distancia. Sin embargo, el hecho de que su comportamiento pueda ser descrito matemáticamente y controlado técnicamente exige su inclusión en la realidad física ordinaria de nuestra cultura científica occidental.

En culturas tradicionales, uno de los contextos donde la transformación de experiencias extraordinarias en ordinarias ocurre con más fre- 
cuencia es el de los procesos vocacionales o iniciáticos por los que pasan quienes luego ejercen como expertos en el trato con realidades y poderes suprahumanos: exorcistas, chamanes, magos, sanadores, brujos etc.

De acuerdo con numerosos estudios antropológicos, estos procesos suelen comprender una etapa inicial, caracterizada por la vivencia de experiencias extraordinarias, y un periodo más o menos largo de aprendizaje, donde el sujeto va poco a poco adquiriendo las técnicas necesarias para controlar al menos algunos aspectos de este tipo de vivencias ${ }^{17}$.

El carácter extraordinario de las experiencias iniciales se manifiesta externamente en el impacto que tienen sobre la conducta del sujeto, al que sumergen en una crisis de desorientación existencial más o menos aguda. Suelen comenzar de forma espontánea y en muchos casos producen síntomas físicos y conductuales parecidos a los de algunas enfermedades mentales: terrores, ataques de angustia, lapsus prolongados, fugas. Lo más frecuente es que, en los primeros momentos, tanto el sujeto como su entorno social inmediato interpreten estas vivencias como el efecto de algún trastorno físico y procuren poner los medios terapéuticos adecuados. Pero cuando los remedios fallan y los síntomas se perpetúan o agudizan, suele considerarse la posibilidad de que tengan un origen suprahumano.

Evidentemente, para que esta segunda interpretación sea posible, el sujeto en cuestión o el grupo humano al que pertenece deben creer en la existencia de este tipo de fuente causal, o estar dispuesto a considerar su posibilidad. En aquellas sociedades equipadas con una tradición religiosa o cosmológica que avale la creencia en fuentes suprahumanas de poder suelen existir tipos sociales especializados en interpretar los signos que delatan su acción. Estas personas, a las que calificaré como "mistagogos", son también capaces de discernir las razones por las que tales poderes afectan al sujeto en cuestión y de instruirle para que sepa cómo responder a ellas de forma adecuada.

La etapa posterior de aprendizaje se realiza casi siempre bajo la guía de algún mistagogo experimentado que, además de conocer técnicas para

17 Eliade, M., Le chamanisme et les techniques archaïques de l'extase, Éditions Payot, Paris 1983, pp. 44-69; Ioan M. Lewis, Ecstatic religions. An Anthropological study of spirit possession and shamanism, Penguin Books, Harmondsworth 1978, pp. 66-99; WALSH, R.N., The spirit of shamanism, HarperCollins Publishers, London 1990, pp. 34-41; RANDAL, P. Geekie, J.- LAmbrecht, I. - TAITIMU, M., "Dissociation, psychosis and spirituality: Whose voices are we hearing?: MoskowitZ, A.- SHÄFER, I. - DorAhy, M.J., (eds), Psychosis, trauma and dissociation: Emerging perspectives on severe psychopathology, John Wiley \& Sons 2008, pp. 333-345. 
controlar lo extraordinario es capaz de ofrecer una interpretación culturalmente aceptada de sus manifestaciones. A medida que el aprendiz va siendo capaz de dar sentido a sus experiencias y de controlar ciertos aspectos de las mismas, va adquiriendo seguridad en la interacción con lo extraordinario y, en esa misma medida, las experiencias inicialmente vividas como extraordinarias se van integrando en su vida ordinaria. Si el proceso iniciático no se frustra, el que fuera aprendiz terminará por incorporar en su rango de experiencias cotidianas todo lo que deriva de su práctica experimentada como chamán, exorcista o sanador.

Es importante tener en cuenta que, en los grupos tradicionales, la capacidad de domeñar las experiencias extraordinarias no suele extenderse más allá de los círculos de expertos, por lo que la sociedad en torno no sólo seguirá creyendo en el carácter extraordinario de las experiencias, sino que atribuirá este mismo carácter a la persona que exhibe el poder de controlarlas. Significativamente, la capacidad que adquieren unos de domesticar lo extraordinario les convierte a los ojos de los demás en seres con naturaleza o dones extraordinarios.

El grado en que los distintos tipos de expertos llegan a controlar lo extraordinario es muy variable. Así, mientras que la mayoría de los místicos cristianos declaran sentirse totalmente a merced de la voluntad divina, única responsable de sus inusuales vivencias, los chamanes siberianos o los líderes de los cultos de candomblé o de santería se sienten muchas veces capaces de imponer su voluntad a las entidades espirituales con las que interactúan. En este contexto, el tipo social que los estudios de antropología comparada suelen calificar con el término de "mago" representa al experto con mayor poder de controlar, es decir, al de la persona capaz de manipular técnicamente experiencias que el resto de la sociedad considera altamente extraordinarias.

La tensión que surge entre aquello que de incontrolable tienen las experiencias extraordinarias y el afán de ciertas personas o grupos por propiciar o controlar al menos parcialmente su manifestación constituye, seguramente, una de las fuentes del comportamiento ritual humano ${ }^{18}$.

\footnotetext{
18 En este sentido entiendo la consideración que Ann Taves otorga al comportamiento ritual como una de las estrategias adoptadas por los seres humanos para conseguir ciertos objetos o metas a los que ascriben un valor incomparable. Dado que lo incomparablemente valioso no suele ser fácilmente accesible ni controlable, es lícito considerar que las experiencias extraordinarias pueden constituir metas de este tipo: TAVES, Religious experience reconsidered, pp. 46ss, 175.
} 
Algunas formas de comportamiento ritual humano podrían, en efecto, tener su origen en el afán de los grupos por repetir ciertos tipos de experiencias extraordinarias vividas de forma espontánea por alguno de sus miembros o por algún antepasado ilustre. Aquí no se trataría tanto de controlar los contenidos de la experiencia como de revivirla. Dado que el carácter extraordinario de la experiencia la hace, por definición, incontrolable e incomprensible, lo único que el grupo puede probar de hacer para provocarla es reproducir lo más fielmente posible las circunstancias que se dieron en su primer acontecer. La idea que en estos casos subyace al afán por la reproducción fiel de escenarios y acciones es recrear las condiciones que pudieron favorecer la experiencia originaria, aun ignorando todo o casi todo sobre los procesos causales implicados. Esta actitud práctica, que prescinde de razonamientos causales pero cree en la eficacia de la repetición de pautas estereotipadas, es precisamente una de las propiedades que caracterizan el comportamiento ritual.

En la medida en que un comportamiento ritual orientado a provocar algún tipo de experiencia extraordinaria es considerado efectivo y es institucionalizado como rito, la experiencia que supuestamente produce adquirirá un cierto carácter ordinario. Ejemplos claros de esta situación son los ritos de candomblé, vudú o santería que intentan provocar la posesión de los participantes por parte de algunas de las entidades espirituales a las que dichos cultos están dedicados ${ }^{19}$. Aunque cada persona poseída pueda experimentar algunas novedades inesperadas, las manifestaciones de los diferentes espíritus en ellas se adaptan normalmente a unas pautas que permiten reconocer la entidad poseedora y convierten la experiencia de posesión en algo relativamente predecible y ordinario.

Uno de los casos más extremos de transformación de una experiencia extraordinaria en ordinaria es el sacramento católico de la confirmación, en el que el carácter extraordinario de la recepción del Espíritu por parte de los primeros cristianos ya sólo está presente como contenido de fe. Los candidatos a recibir la confirmación creen que reciben el Espíritu y que semejante acontecimiento es por sí mismo extraordinario, pero sus experiencias en el transcurso del rito suelen ser totalmente ordinarias.

Antes de finalizar este apartado quiero llamar la atención sobre el hecho de que la interpretación de una experiencia extraordinaria por

19 MÉtraux, A., Le vaudou haïtien, Gallimard 1958, pp. 106-125; BASTIDE, R., Le candomblé de Bahia. Transe et possession du rite du Candomblé (Brésil), Brodard \& Taupin, Plon 2000, pp. 217-250. 
parte del sujeto hace que su carácter extraordinario decrezca irremediablemente en algún grado. Si el sujeto sabe interpretar lo que experimenta, ya no le resultará absolutamente extraño, ya sabrá situarlo en algún contexto conocido, ya será capaz de reconocer algunos aspectos de lo que está viviendo. Evidentemente, la interpretación es una noción que admite muchos grados. La mera identificación de modalidades sensoriales en una experiencia puede considerarse un principio, aunque ínfimo de interpretación. La interpretación más completa de una experiencia sería, en el otro extremo, su inclusión coherente en una teoría que diera cuenta de cada uno sus detalles y matices.

En este punto, considero pertinente hacer notar que el interés de este estudio se centra sobre todo en experiencias extraordinarias parcialmente interpretadas o en proceso de interpretación. Es decir, en experiencias que conservan aspectos extraordinarios pero que el sujeto o grupo que las reconoce intenta dotar de sentido. Una experiencia extraordinaria que no suscitara en nadie interés alguno por ser interpretada, se convertiría antes o después en una anécdota irrelevante tanto para el sujeto que la ha experimentado como para la sociedad en torno, quienes probablemente acabarían olvidándola. Esto es lo que suele suceder con los sueños cuando el sujeto no los valora ni como medio de comunicación con el más allá ni como información psicoterapéuticamente relevante.

\section{Interpretación, alteridad y novedad}

Los seres humanos tenemos una tendencia espontánea a interpretar nuestras experiencias conscientes. De hecho, todo parece indicar que una experiencia totalmente despojada de interpretación sería inútil desde el punto de vista cognitivo.

La interpretación de las experiencias por parte del sujeto es un proceso todavía poco conocido, que parece desenvolverse en múltiples niveles -el neurológico, el sensorio-motor y el sociocultural- entre los más generales y discernibles. No obstante, todos los expertos están de acuerdo en que la interpretación más básica y cotidiana, la que constituye la percepción sensible en la experiencia ordinaria, se inicia de forma espontánea a nivel inconsciente y que, antes de emerger a la conciencia, ya ha adquirido un importante grado de complejidad ${ }^{20}$.

20 FAUCONNIER - TURner, The way we think, pp. 3-15. 
En el sujeto adulto, la interpretación de sus interacciones ordinarias con otros seres humanos y con los ámbitos naturales y culturales donde se desenvuelve su vida cotidiana también tiene mucho de automático, aunque en este caso los automatismos han sido adquiridos a través de la socialización primaria, la costumbre y la educación.

Esta actividad interpretativa espontánea que configura de forma casi inmediata la experiencia ordinaria tiene, para la especie humana, un carácter adaptativo. Sirve para que el sujeto sea capaz de reaccionar con poco esfuerzo y de forma eficaz en las situaciones típicas o recurrentes de su vida cotidiana. Esta indudable ventaja nos impide, sin embargo, decidir voluntariamente los criterios con los que constituimos, identificamos y tipificamos la mayor parte de las entidades que forman nuestro mundo. Semejante impotencia afecta también a la manera como el sistema cognitivo humano opera en las experiencias extraordinarias.

Uno de los momentos más importantes del proceso de interpretación de una experiencia es la clasificación genérica de su origen como propio o ajeno. Esta clasificación, que también tendemos a hacer de forma espontánea, pretende distinguir entre lo creado por el propio sujeto, como es por ejemplo el caso de un pensamiento, y lo que nos parece se origina en una realidad distinta, es decir, en el ámbito de alteridad. Aunque semejante distinción parece muy clara en las interacciones habituales con el marco físico donde se mueve nuestro cuerpo, hay muchas situaciones en las que resulta confusa o es incluso imposible de aplicar. Esto último sucede con cierta frecuencia en el ámbito de las emociones y sensaciones corporales y, de forma muy conspicua, en algunos tipos de experiencias extraordinarias.

De hecho, desde hace más de dos década, las investigaciones neurológicas y psicológicas señalan con creciente insistencia que no es posible trazar una línea divisoria neta entre los aspectos activos y pasivos de nuestra interacción sensible y cognitiva con el mundo. La visión, por ejemplo, no es el resultado de la recepción pasiva de estímulos producidos por fotones en nuestra retina, sino la generación de un campo visual simulado que integra, además de esos estímulos, una cantidad enorme de información procesada en distintas partes del cerebro y procedente tanto de otras modalidades sensibles como de la memoria ${ }^{21}$.

Ahora bien, debido probablemente a las ventajas adaptativas que ello conlleva, las dinámicas espontáneas de nuestros procesos cognitivos

21 Stone, James V. Vision and Brain. How We Perceive the World, London 2012. 
están modeladas sobre la vida práctica y tienden, por tanto, a atribuir el origen, la causa o el fundamento de cuanto creemos experimentar pasivamente a una alteridad real. Esta segunda tendencia juega un papel fundamental en la interpretación de todas nuestras experiencias, tanto las ordinarias como las extraordinarias. La diferencia está en que a las causas reificadas de las experiencias ordinarias las integramos sin problema en la realidad ordinaria, mientras que las causas reificadas de lo extraordinario son, por definición, realidades trascendentes.

Como parte del proceso por el que el sujeto determina las realidades que supuestamente provocan su experiencia está su intento de situarse en el espacio y en el tiempo que comparte con ellas. Está, también, su afán por responder a cuestiones como: ¿cuál es la naturaleza de esta realidad? ¿cómo me afecta?, ¿puedo yo actuar sobre ella?, ¿podemos comunicarnos?, ¿está ahora presente o es, por el contrario, algo imaginado, recordado, soñado ...?

Un factor decisivo a la hora de responder el sujeto a este tipo de cuestiones es la percepción que durante la experiencia tenga de su propio cuerpo, especialmente de sus límites y de su capacidad para relacionarse con lo que concibe como alteridad. No es, pues, casualidad que lo extraordinario de muchas experiencias extraordinarias esté vinculado a formas inusuales de sentir el propio cuerpo y su relación con el entorno -viajes celestes o chamánicos, fusión con el todo o experiencia oceánica, experiencias extra-corporales, cambios de identidad-, etc.

Por supuesto, la interpretación de la experiencia no termina necesariamente en la elaboración de la percepción y la sensación del presente. Es propio de la mente humana expandir y enriquecer el proceso interpretativo con la ayuda de otros recursos cognitivos, como la memoria en sus distintas modalidades y la búsqueda de coherencia con lo ya aprendido.

El nivel más elaborado de interpretación se lograría cuando la experiencia en cuestión quedara total y coherentemente integrada en una teoría o visión global de las cosas que diera razón, no sólo de ella, sino también de todas las experiencias semejantes vividas en el pasado, conocidas de forma indirecta, o imaginadas como posibles en el futuro. Ésta ha sido una aspiración frecuente entre los sistemas tradicionales de pensamiento religioso o metafísico, aunque hoy, tras la crítica de la filosofía postmoderna al conocimiento sistemático, muy pocos la considera factible. Ahora bien, puesto que la especie humana ha demostrado en todas las épocas y culturas que tiene la capacidad de vivir experiencias extraordinarias, no debe sorprendernos que los sistemas tradicionales de pensamiento recep- 
tivos a este dato optaran mayoritariamente por afirmar la existencia de realidades trascendentes. Esto explica que, no sólo las mitologías populares, sino también muchos sistemas racionalmente elaborados de pensamiento religioso y metafísico hablen de ámbitos celestes, seres de naturaleza divina y acontecimientos extraordinarios producidos por entidades trascendentes.

Lo extraordinario de la experiencia extraordinaria se caracteriza precisamente por ser incontrolable, inexplicable e impredecible para el sujeto. La impotencia que éste siente frente a lo que desborda de este modo sus capacidades cognitivas le fuerza a reconocerse sujeto pasivo de una alteridad que se le impone. Pero, como su misma incapacidad para controlar y entender esa alteridad le impide integrarla en la realidad ordinaria, las únicas opciones cognitivas que se le ofrecen son atribuirle una realidad trascendente o suspender momentáneamente el juicio sobre lo vivido en espera de nuevas experiencias que arrojen luz sobre el asunto.

Evidentemente, para que la primera opción sea posible, la cultura en la que ha sido socializado el sujeto tiene que afirmar o al menos admitir como verosímil la existencia de realidades distintas a la de la vida cotidiana. Esta actitud ha sido la más frecuente entre las culturas históricas y lo sigue siendo entre las culturas no científicas actuales.

La segunda opción es frecuentemente el comienzo de una larga búsqueda intelectual y/o espiritual que puede desembocar en la reafirmación de creencias tradicionales sobre la realidad trascendente, en el descubrimiento de entidades hasta el momento desconocidas de la realidad ordinaria, o en el reconocimiento de nuevas dimensiones o realidades trascendentes ignoradas por la tradición.

En cualquier caso constatamos que las experiencias extraordinarias constituyen un serio reto para las capacidades cognitivas del ser humano. Cuantos más elementos o aspectos extraordinarios tenga una experiencia más difícil será para el sujeto interpretarla con los criterios con los que interpreta su vida cotidiana. La resistencia de estos elementos a dejarse integrar en la realidad ordinaria provoca perplejidad e incertidumbre cognitiva, lo cual favorece la disposición del sujeto a buscar, imaginar, crear o construir teorías o realidades con las que intentar aprehender la nove$\mathrm{dad}^{22}$.

22 Un caso ilustrativo del tipo de tensión que viven los sujetos de experiencias extraordinarias en su esfuerzo por integrarlas puede encontrarse en: RANDAL - GEEKIE - LAMBRECHT - TAITIMU, “Dissociation, psychosis and spirituality: Whose voices are we hearing?". 
Formulando las cosas de otra manera diremos que la capacidad humana para tener experiencias extraordinarias proporciona ocasiones y acicates al sistema cognitivo del sujeto para hacerse con lo que se le presenta como novedad irreducible. Esta forma de considerar las cosas es coherente con el dato, confirmado tanto por la psicología como por la antropología, de que la mayor parte de las experiencias extraordinarias espontáneas ocurren, precisamente, en sujetos que atraviesan crisis cognitivas, emocionales, éticas o existenciales. Tales crisis surgen cuando el bagaje de presupuestos y conocimientos con los que hasta el momento operaba el sujeto se revela insuficiente o ineficaz para seguir guiando su pensamiento y su acción en un presente novedoso. En estas situaciones, el carácter extraordinario de la experiencia puede propiciar que la conciencia del yo se rinda en su empeño por entender lo nuevo a partir de lo viejo, por controlar la coherencia de su sistema previo de conocimientos, y expanda el horizonte de su percepción y de su comprensión. La crisis induce una pérdida de control consciente sobre la atención selectiva y deja que la mente sea afectada por aspectos del organismo, del entorno y del universo a los que previamente no era receptiva.

Frente a la tendencia predominante en nuestra vida despierta cotidiana a focalizar la atención sobre actividades rutinarias y pautas de pensamiento estándar, y a desechar de la conciencia todo lo que no es coherente con lo ya sabido y relevante para una praxis eficaz, las experiencias extraordinarias violentan la mente acomodada incitándola a considerar la novedad radical. La apropiación de esa novedad por el sistema cognitivo del sujeto cambia al propio sujeto y a su relación con el entorno ${ }^{23}$. En un universo tan cambiante como es el de la especie humana, no es absurdo pensar que la sensibilidad a lo extraordinario pueda haber llegado a ser una ventaja adaptativa y un acicate para el cambio cultural.

Lejos, pues, de pensar que la sensibilidad para lo extraordinario es indicio de incultura, patología o superstición, parece más acertado considerarla una potencialidad del sistema cognitivo humano que permite o facilita cambios bruscos en los paradigmas mentales inducidos por la praxis cotidiana o heredados de la cultura.

Evidentemente, para que el cambio personal provocado por experiencias extraordinarias genere cambio cultural es preciso que el sujeto

23 MCnamara, P., The neuroscience of religious experience, Cambridge University Press, New York 2009, estudia las trasformaciones de la identidad operadas por la incorporación de información a través de los sueños y ritos inductores de experiencias religiosas. 
sea capaz de comunicar y compartir sus nuevas convicciones a un grupo suficientemente grande de personas. Un ejemplo histórico muy claro de este fenómeno lo encontramos en los orígenes del cristianismo. En efecto, tras la muerte de Jesús, sus seguidores fueron afectados por visiones y otras experiencias extraordinarias que interpretaron en términos de exaltación y resurrección de su líder crucificado. Espoleados por la novedad que dicha interpretación forzó en su sistema de creencias y de prácticas, formaron un grupo de adeptos que extendió su nueva forma de vivir y de pensar por todo el Mediterráneo, cambiando para siempre el panorama cultural de esta zona del mundo.

Evidentemente, no todos los cambios subjetivos motivados por experiencias extraordinarias pueden considerarse positivos. Basta pensar en las experiencias perturbadoras de los pacientes esquizofrénicos o de las víctimas de supuestas posesiones demoníacas. Incluso entre sujetos inicialmente sanos, la irrupción de lo extraordinario en la conciencia no se resuelve siempre de forma ventajosa. En algunas ocasiones el sujeto es incapaz de integrar coherentemente lo radicalmente extraño y acaba siendo engullido por procesos de desintegración de la personalidad, con graves consecuencias psíquicas y sociales ${ }^{24}$. Esto no invalida, sin embargo, la hipótesis de que poseer una mente susceptible de tener experiencias extraordinarias capaces de motivar cambios bruscos en su forma de entender su relación con la alteridad sea una ventaja adaptativa para la especie humana en su conjunto.

\section{Experiencias extraordinarias y alteraciones mentales y neurológicas}

Como he señalado anteriormente, una experiencia puede ser extraordinaria en una cultura y no serlo en otra. Es decir, puede contradecir aspectos de la experiencia ordinaria construida por un determinado grupo humano, pero no la experiencia ordinaria básica que compartimos todos los seres humanos en virtud de nuestro tipo común de organismo.

También hay experiencias que pueden ser extraordinarias para un individuo particular pero no incluyen nada que contradiga la experiencia ordinaria de su propia cultura. Son experiencias que sólo son extrañas e imprevisibles para el individuo en virtud de su anterior personalidad y trayectoria vital. Este tipo de experiencias, a las que solemos calificar como particularmente intensas, iluminadoras o profundas, son frecuentes en

24 MCNAMARA, The neuroscience of religious experience, pp. 57, 167-170. 
el conjunto de cualquier población suficientemente numerosa. Incluyen experiencias estéticas intensas, experiencias de oración profunda, de contemplación intelectual, de inmersión en la naturaleza etc. Una clase muy frecuente son las experiencias individuales de conversión a una creencia religiosa o a una filosofía, que pueden ser vividas por sus protagonistas como vivencias extraordinarias debido al cambio brusco de perspectiva vital que implican, a las emociones intensas que han propiciado o seguido a ese cambio, a la convicción de que se ha dejado atrás una visión equivocada del mundo, un camino de perdición, un estilo de vida errado ... pero que no contienen nada que otro individuo de la misma cultura tuviera necesariamente que considerar extraordinario.

Ahora bien, hoy día tenemos amplia evidencia antropológica, psicológica y neurológica de que los seres humanos también podemos tener experiencias extraordinarias de un tipo mucho más radical, experiencias que entran en conflicto con la experiencia ordinaria básica de la vida despierta común a toda nuestra especie. Estas experiencias son menos frecuentes y contienen aspectos o elementos que desconcertarían a cualquier persona que no estuviera habituada a inducírselas artificialmente. Suelen ser reconocibles para observadores externos por las actitudes, gestos o comportamientos del sujeto que las experimenta. Los casos más claros conllevan alteraciones importantes en la manera como el sujeto percibe, siente y relaciona distintos contenidos de conciencia ${ }^{25}$.

Aunque los procesos psicológicos y neurológicos subyacentes a estos tres grandes tipos de experiencias extraordinarias son, probablemente, muy distintos, las hemos catalogamos a todas como "extraordinarias" porque el sujeto las vive como acontecimientos críticos e inesperados, que contradicen los presupuestos de su vida cotidiana y le fuerzan o motivan a hacer ajustes cognitivos.

Las variedades de experiencias extraordinarias reconocidas por la antropología, que, por lo demás, se asemejan bastante a las de testimonios históricos procedentes de religiones y culturas tradicionales, incluyen aspectos identificados por la psicología y la neurología, pero hoy por hoy es imposible establecer una correspondencia clara entre los resultados de una y otras ciencias. La principal dificultad que presentan las fuentes antropológicas es que suelen interesarse más por la interpretación de la

\footnotetext{
25 Ver la recopilación de casos acreditados y clasificados de acuerdo con criterios psicológicos: TART, C. T. (ed.), Altered states of consciousness. A book of readings, John Wiley \& Sons, New York - London - Sydney - Toronto 1969.
} 
experiencia en términos de realidades trascendentes que por la descripción del fenómeno experiencial. Así, por ejemplo, un visionario cristiano del siglo I hablará directamente de Cristo resucitado viniendo entre las nubes, sin detenerse a describir las sensaciones y percepciones que llenaban y componían su campo visual en el momento de la experiencia.

A pesar de esta falta de equivalencia entre los testimonios de quienes tienen experiencias extraordinarias y los conceptos técnicos de la psicología y la neurología, disponemos hoy de una serie de resultados científicos consensuados que justifican este esfuerzo por crear un modelo conceptual coherente para hablar de ellas.

El uso controlado de ingestión de drogas, ejercicios corporales y prácticas ascéticas así como diversos experimentos neurológicos han permitido constatar que la conciencia humana puede experimentar alteraciones importantes respecto a sus estados habituales en la vida despierta orientada a la praxis cotidiana. Las alteraciones más frecuentes estudiadas por la psicología y la neurología afectan a (1) la sensibilidad externa, (2) la sensibilidad interna, (3) el proceso de información en distintos niveles (4) la memoria en sus distintos tipos y manifestaciones, (5) el subconsciente freudiano (6) las emociones, (7) los procesos de evaluación y toma de decisiones, (8) el sentido del espacio y del tiempo, (9) el sentido o noción de la propia identidad, y (10) la capacidad de movimiento e interacción con otras entidades (agencia) ${ }^{26}$. Significativamente, una proporción importante de estudios y testimonios antropológicos e históricos sobre experiencias extraordinarias mencionan o parecen presuponer algunas de estas alteraciones ${ }^{27}$.

A los episodios de la vida consciente en los que se producen alteraciones notables de la conciencia respecto a los estados habituales de la experiencia ordinaria los denominaremos "estados alterados de conciencia" $(\mathrm{EAC})^{28}$.

26 TART, States of consciousness, iUniverse.com, Inc., Lincoln 1983, pp. 6-7, 90-139.

27 Ver, por ejemplo, los casos estudiados por John Pilch en la cultura mediterránea antigua: PILCH, J. J., "Altered States of Consciousness: A "Kitbashed" Model”, BTB 26.3, 1996, 133-138; "Appearances of the Risen Jesus in Cultural Context: Experiences of Alternated Reality", BTB 28.2, 1998, 52-60; "Holy Men and Their Sky Journeys: A CrossCultural Model", BTB 35.3, 2005,106-111.

28 Aunque esta denominación es discutida y matizada por muchos estudiosos, es la que de forma más general se ha impuesto en el estudio de estados anormales pero no patológicos de la conciencia. CARdeña, E. - Winkelman, M. (eds), Altering consciousness. Multidisciplinary perspectives. Volume 1: History, culture, and the humanities. Volume 2: Bio- 
Es importante sin embargo subrayar que la cultura, la trayectoria vital y las características individuales pueden influir tanto en el repertorio de estados de conciencia habituales en la experiencia ordinaria como en el repertorio de estados alterados de conciencia accesibles para el sujeto.

La investigación neurológica reciente avala la idea de que algunos tipos de EAC están asociados a modalidades o dinámicas de funcionamiento del sistema nervioso que difieren en algunos aspectos importantes de las que caracterizan el funcionamiento neurológico en el repertorio básico de estados de conciencia compartidos por todos los seres humanos. Muchas de estas modalidades y dinámicas no ordinarias parecen implicar cambios significativos en la configuración y conductividad de las interconexiones de distintos circuitos neuronales ${ }^{29}$. Estos cambios implican, a su vez, que el sistema nervioso integrará y procesará la información que recibe, tanto del propio cuerpo como de su entorno, de formas distintas a las habituales.

Las observaciones anteriores sugieren con fuerza que muchas de las experiencias extraordinarias reseñadas por los testimonios antropológicos e históricos se han producido en estados alterados de conciencia, y que éstos, a su vez, habrían estado acompañados de dinamismos atípicos en el sistema nervioso de los correspondientes sujetos.

En este punto es importante insistir en que ni los funcionamientos neurológicos atípicos ni los estados alterados de conciencia implican necesariamente una percepción falsa de la "realidad". Como ya he explicado en apartados anteriores, la realidad es siempre una construcción, tanto la realidad ordinaria de un determinado grupo cultural, como las realidades trascendentes sugeridas por las experiencias extraordinarias o postuladas por los sistemas de pensamiento filosófico-religiosos.

Ciertamente, la realidad ordinaria goza de la ventaja del consenso del grupo, el cual organiza su vida sobre el presupuesto de que la experiencia ordinaria refleja la configuración de un mundo real estable. Sin embargo esto no autoriza a considerarla como la única auténtica en contraposición a otras construcciones supuestamente falsas de la realidad. De hecho, también la realidad ordinaria, presupuesta y consensuada por el grupo, cam-

logical and psychological perspectives, Praeger, Santa Barbara, California - Denver, Colorado - Oxford, England 2011.

29 Newberg, A. - D'AQuili, E. - Rause, V., Why God won't go away. Brain science and the biology of belief, Ballantine Books, New York 2001. Ver especialmente el capítulo 3: Brain architecture. 
bia a medida que las nuevas experiencias grupales y los avances científicos y técnicos modifican el conocimiento social compartido. Basta, para darse cuenta de esto, comparar la concepción de la realidad ordinaria propia de nuestra cultura posmoderna occidental, en la que integramos numerosas teorías científicas altamente sofisticadas, con la vigente en la Antigüedad, la Edad Media o, incluso, el Renacimiento.

Los funcionamientos neurológicos involucrados en los distintos EAC seleccionan, procesan y configuran la información de forma atípica, por lo que, a la hora de interpretar su experiencia, el sujeto encuentra dificultades o impedimentos para atribuirla a la realidad de la vida cotidiana. Por tanto, en la medida en que logre dar una interpretación satisfactoria a su experiencia, la realidad que construya para explicarla será distinta de la realidad de su vida cotidiana. Sin embargo, no tiene sentido preguntar si una será más falsa o más verdadera que la otra. Lo único que es legítimo plantear respecto a ellas es en qué medida son biológica y/o culturalmente adaptativas.

La historia, la psicología social y la antropología cultural han mostrado que los entornos humanos excesivamente tradicionalistas y conservadores favorecen formas de rigidez mental que, en contextos de cambio, pueden convertirse en obstáculos para la adaptación individual y colectiva. En semejantes circunstancias, las experiencias extraordinarias producidas por EAC pueden ser ventajosas para los individuos, pues les motivan a realizar ajustes cognitivos novedosos, aumentando así sus posibilidades de adaptarse al cambio ${ }^{30}$. No es probablemente casualidad que muchos líderes políticos y sociales, así como muchas personalidades innovadoras en los ámbitos del conocimiento, de la religión, de la ética y del arte hayan encontrado motivación, inspiración y convicción en experiencias extraordinarias.

El conocimiento científico de los procesos y mecanismos neurológicos que subyacen los aspectos extraordinarios de las experiencias extraordinarias es todavía parcial e imperfecto, pero ya existen algunas hipótesis generales ampliamente consensuadas que pueden ayudarnos a entender mejor la funcionalidad de estas experiencias.

La primera de ellas es que el sistema nervioso y en particular el cerebro es mucho más flexible y versátil de lo que hasta hace relativamente

30 Whitehead, C. T., "Altered consciousness in society" en: CARdEÑa - WinkeLMAN, Altering consciousness. Vol 1, 181-202, pp. 188-189; FACHNER, J., "Time is the key: music and altered states of consciousness", Idem, 355-376, p. 362. 
poco se pensaba. Las conexiones neuronales pueden cambiar de forma drástica y con relativa rapidez bajo los efectos de las hormonas, de sustancias ingeridas, prácticas de concentración, aprendizajes motores, la memorización y la imitación.

Las rutinas de la vida despierta cotidiana refuerzan unos circuitos y unas interconexiones neuronales a costa de otras, creando numerosos automatismos tanto a nivel de reacciones motoras como de la atención. Esto facilita la ejecución fluida de nuestras actividades habituales, pero también impone sesgos en la atención y la conciencia. En nuestra vida cotidiana ignoramos gran cantidad de información interna y externa que es accesible a nuestro cerebro pero que la orientación práctica de nuestra conciencia despierta descarta como irrelevante 31 . No es, pues, absurdo pensar que en estados de conciencia no ordinarios podamos sentir, percibir, recordar y aprehender objetos distintos o con matices distintos a los que capta nuestra conciencia ordinaria ${ }^{32}$.

Sabemos también que el sistema nervioso incluye diversos subsistemas algunos de los cuales pueden funcionar integrados en redes de interconexiones o de forma autónoma. Además, las posibles interconexiones entre ellos pueden ser más o menos intensas. Esta compleja organización permite que la información que llega a la conciencia pueda provenir de distintos conjuntos de subsistemas y adquirir distintos grados de relevancia. Así, por ejemplo, es posible que la conciencia de ciertas emociones o sensaciones internas adquiera mucho más peso del ordinario y coloree o incluso modifique otros contenidos de la experiencia de forma inusitada. Algunos autores relacionan la desconexión de ciertos subsistemas de sensaciones internas con la percepción alterada de los límites corporales o, incluso, la ausencia de los mismos. Esto último podría explicar aspectos involucrados en algunas experiencias místicas de unión: la disolución del individuo en el todo o en una alteridad oceánica ${ }^{33}$.

La alteración de la conductividad de las conexiones neuronales dentro de ciertos circuitos o subsistemas también puede tener consecuencias muy destacadas en la experiencia consciente. Pensemos, por ejemplo, en el subsistema sensorio-motor, que relaciona sensaciones externas con las

\footnotetext{
31 Newberg - D'AQuili - Rause, Why God won't go away, sección: The seat of the will. Explica los mecanismos por los que que el área cerebral asociada a la atención rechaza información inútil para la actividad en la que está implicado el sujeto.

32 KoкоszKa, States of consciousness, p. 125.

33 D'aquili, E. - Newberg, A., The mystical mind. Probing the biology of religious experience, Fortress Press, Minneapolis 1999, pp.41-42.
} 
reacciones motoras, o en los sistemas de neuronas espejo que además de permitir el aprendizaje motor por imitación nos hacen capaces de sentir el estado emocional de otra persona a partir de la percepción de su expresión corporal ${ }^{34}$. Las modificaciones en los flujos de información que recorren estos subsistemas pueden modificar de forma drástica la manera de percibir nuestra relación con el escenario en el que situamos nuestro cuerpo y con las manifestaciones emotivas de las figuras humanas.

Especialmente interesante es la teoría de Wildman sobre las experiencias profundas, uno de los tipos de experiencias extraordinarias más frecuentes en contextos religiosos, y cuyo carácter extraordinario se deriva más de los sentimientos que las acompañan que de sus propios contenidos $^{35}$. Según este autor, dichas experiencias estarían propiciadas por una convergencia inusitada de información en el sistema cognitivo del sujeto. Dicha convergencia, cuya causa inmediata habría que buscarla en la intensificación y/o incremento atípico de ciertas conexiones neuronales, desbordaría los cauces que habitualmente constriñen nuestra atención, abriendo las compuertas de la conciencia a una cantidad y variedad anormal de datos. La inundación informativa de la conciencia no sólo facilitaría la síntesis creativa de nuevas ideas, conceptos o imágenes, sino que sería también responsable de la génesis de ciertos sentimientos muy intensos que son, por sí mismos, capaces de conferir a la experiencia un carácter extraordinario.

Así, cuando la conciencia anegada por la información se percibe a sí misma sin control sobre lo que le acontece, surge frecuentemente en ella un sentimiento muy fuerte de abandono confiado en la Alteridad de la que se siente depender. Sin embargo, cuando lo que sobresale en la experiencia es la conciencia de separación respecto a la fuente de la información que la desborda, surge, por el contrario, el típico sentimiento de temor religioso reverencial que provoca en el sujeto actitudes de sometimiento.

En aquellos casos en que lo que llama prioritariamente la atención de la conciencia es la inmensidad de lo dado, la experiencia favorecerá bien un sentimiento de vaciamiento o anonadamiento en el Otro, bien el sentimiento de inmersión en un Todo de quietud (calma oceánica). En ambos casos, el sujeto suele reaccionar relativizando su propia identidad, y adoptando actitudes de desasimiento y generosidad.

\footnotetext{
34 MetZinger, The ego tunel, pp.166-174.

35 Wildman, Wesley J., Religious and spiritual experiences, Cambridge University Press, Cambridge - New York 2011, pp. 104-143.
} 
Finalmente, si la conciencia queda prendada de la enorme complejidad de la información que la inunda, los sentimientos y reacciones que típicamente se siguen son de dos tipos. En unos casos priman la curiosidad, la confusión y la ansiedad por entender, ante los que el sujeto reacciona con una admiración activa que se afana por investigar y encontrar coherencias. En otros casos la conciencia se siente abrumada por la propia ignorancia y por su incapacidad para asir lo que se le presenta. La actitud concomitante del sujeto en estas circunstancias es la de profunda reverencia hacia lo que reconoce como una Alteridad inalcanzable, separada por el aura y la barrera de la sacralidad.

Las reflexiones y ejemplos anteriores ponen de manifiesto que el sistema nervioso media en los procesos en los que la conciencia humana construye su propia identidad y la realidad con la que interacciona, y que las posibles alteraciones de dicho sistema pueden modificar nuestra manera de procesar la información accesible a la conciencia e incluso la magnitud y riqueza de la misma. Es posible que la información accesible en estados alterados de conciencia no sea útil para la vida despierta habitual en condiciones ecológicas estables, pero esto no la convierte en falsa, ni excluye la posibilidad de que sí resulte valiosa en contextos vitales altamente variables.

\section{Ideas mínimamente anti-intuitivas.}

\section{La aproximación cognitiva a la religión}

En las últimas décadas, las ciencias cognitivas han irrumpido con fuerza en los ámbitos de la psicología y la antropología de la religión. Aunque su relación con la neurología es todavía muy tenue y su interés por la experiencia extraordinaria muy parcial, la teoría que actualmente defienden muchos antropólogos cognitivos sobre el origen de las ideas religiosas puede, a mi entender, complementar de forma satisfactoria las reflexiones y explicaciones propuestas hasta aquí en este escrito.

Estos antropólogos afirman que lo que unifica a todos los fenómenos culturales vulgarmente denominados "religiones" es la creencia en la existencia de entidades suprahumanas ${ }^{36}$. Con esta expresión se refieren a la

\footnotetext{
36 BOYER, P., The naturalness of religious ideas: A cognitive theory of religion, University of California Press, Berkeley 1994, p.9; PyYsIÄInNEN, I., Supernatural agents. Why we believe in souls, gods and Buddhas, Oxford University Press, Oxford - New York 2009; Tremlin, T., Minds and gods: The cognitive foundations of religion, Oxford University Press, Oxford - New York 2006, p.144.
} 
idea de un ser que posee una psicología semejante a la humana, pero que viola, de forma para él ventajosa, alguna característica propia de los seres humanos. Los ejemplos más claros de este tipo de entidades son los dioses personificados de las diversas mitologías religiosas. Todos ellos pueden ser concebidos como personas que poseen cualidades o capacidades extraordinarias, como hacerse visibles o invisibles a voluntad, dominar sobre los fenómenos naturales, desplazarse a través de barreras sólidas, conocer el pensamiento de los hombres etc. Otros ejemplos muy frecuentes en el panorama de las culturas humanas son el tipo de entidades que en occidente denominamos "espíritus", y que son, fundamentalmente, mentes humanas o humanoides que no están permanentemente ligadas a un cuerpo, aunque puedan poseerlos a voluntad.

Aunque esta definición de religión es, a mi entender, demasiado restrictiva, la observación en que se apoya -la presencia de entidades suprahumanas en las creencias tradicionales de casi todas las culturas- sugiere posibles conexiones con las experiencias extraordinarias. Dicha observación es coherente con la tesis empíricamente avalada de que la memoria humana tiene especial predilección por las ideas (imágenes) mínimamente anti-intuitivas, o dicho de otra manera, que las recuerda con más facilidad y durante más tiempo que otro tipo de ideas ${ }^{37}$. Según la definición propuesta por la antropología cognitiva, una idea es mínimamente antiintuitiva si reproduce una idea previa en todo salvo en un pequeño número de propiedades ${ }^{38}$. Un ejemplo paradigmático de idea mínimamente anti-intuitiva es, precisamente, la de entidad o agente suprahumano, que tan importante papel juega en las culturas tradicionales.

La antropología cognitiva no ha reparado, sin embargo, que las ideas mínimamente anti-intuitivas son el producto de un tipo de proceso cognitivo bastante general, que los seres humanos usamos en multitud de circunstancias. Dicho proceso consiste esencialmente en crear nuevas ideas o representaciones alterando algunas propiedades de ideas ya conocidas. Su campo de aplicación son la multitud de circunstancias en las que la mente humana intenta captar lo nuevo mediante ideas antiguas ligeramente modificadas. Por ejemplo, la física imagina el fotón como una par-

37 PyysiäInNEn, Supernatural agents, pp.22-28; BOYER, The naturalness of religious ideas, p.35; TremLin, Minds and gods, pp.86-93.

38 Aunque Boyer y otros autores insisten en que las ideas implicadas en la formación de ideas anti-intuitivas sean categorías ontológicas generales, comunes a las mentes de todos los seres humanos normales, independientemente de su cultura, mi exposición no exige este requisito: BOYER, The naturalness of religious ideas, pp. 113-118. 
tícula material pero sin masa; la mitología griega imagina a los dioses como seres humanos pero inmortales; los espacios vectoriales de la matemática son como el espacio euclídeo pero con un número cualquiera de dimensiones; el pensamiento tradicional cristiano piensa en un ángel como un joven pero con alas ....

Todo parece indicar que nuestro sistema cognitivo es perezoso y avaro a la hora de invertir esfuerzo en crear nuevas ideas. Siempre que puede, intenta hacer frente a las nuevas experiencias con su bagaje de representaciones previamente aprendidas. Si ninguna de ellas es capaz de reflejar satisfactoriamente los rasgos novedosos, pero hay alguna que parece estar cerca de conseguirlo, intentará eliminar o modificar alguna de sus propiedades o añadir alguna otra para ver si de este modo lo logra. No es infrecuente que en el esquema básico de una idea conocida se introduzcan o sustituyan unas propiedades por otras pertenecientes a una idea diferente. En otras palabras, nuestro sistema cognitivo monta y desmonta elementos y estructuras de ideas conocidas con el fin de crear nuevas representaciones capaces de reflejar la novedad. De esta manera, aprovecha todo lo posible las vías que previamente controlaba en su acceso a la realidad, reconociendo, sin embargo, las modificaciones que debe hacer a fin de que lo nuevo recién descubierto quede también reconocido y reflejado.

En principio, esta estrategia cognitiva sólo altera las ideas de las que parte en la menor medida posible; es decir, sólo cambia en ellas aquello que es estrictamente necesario cambiar a fin de que sirvan a su nueva función representadora o designativa. Gran parte de sus productos finales serán, pues, representaciones o ideas mínimamente anti-intuitivas.

Por tanto, parece legítimo pensar que la presencia de ideas mínimamente anti-intuitivas en el acervo cultural de muchos grupos humanos no se explica sólo por el hecho de que son fáciles de memorizar, sino también por su alto rendimiento cognitivo en situaciones donde la mente humana se enfrenta con la novedad.

Ahora bien, un tipo de contexto especialmente abierto a la novedad es, precisamente, el de las experiencias extraordinarias. Aunque la extrañeza extrema de lo extraordinario puede bloquear temporalmente la creatividad de nuestro sistema cognitivo, una vez finalizada la experiencia, el afán humano por dar sentido a todo cuanto acontece tenderá a prevalecer. Será, pues, sobre todo entonces cuando el sujeto se esfuerce de forma activa por apresar cognitivamente lo vivido, poniendo en marcha la estrategia creadora de representaciones mínimamente anti-intuitivas que acabamos de considerar. Es, por tanto, plausible pensar que, en circunstancias adecuadas, las experiencias extraordinarias pueden ser una fuente espe- 
cialmente productiva de este tipo de representaciones. Numerosos testimonios tradicionales así como el examen atento de los sueños soportan esta suposición ${ }^{39}$.

La hipótesis de que muchas representaciones de agentes suprahumanos pueden haber sido originadas en el contexto de experiencias extraordinarias tiene, a mi entender, una gran capacidad explicativa. Sabemos, en efecto, y de forma empírica, que entre las alteraciones perceptivas frecuentes en este tipo de experiencias están las que afectan al propio cuerpo. Como vimos en apartados anteriores, algunas de estas alteraciones hacen que el sujeto se sienta distanciado de su cuerpo al que ve en perspectiva, como si fuera el de otra persona. Si el sujeto interpreta este tipo de experiencias de forma realista, es decir, construyendo una realidad supuestamente capaz de originarlas, no podrá evitar concluir que su identidad es independiente de su corporeidad, o al menos de la forma específica de corporeidad que tiene en su vida ordinaria. Muchos sueños apoyan también esta conclusión, pues no es infrecuente en ellos que el sujeto encarne distintos personajes o que un tercero cambie súbitamente de cara, con el consiguiente cambio de identidad. Si el rostro que emerge en alguno de estos sueños es, además, el de un allegado fallecido, la hipótesis de que su mente, separada del cuerpo ya muerto, sigue existiendo en algún tipo de realidad trascendente adquirirá gran verosimilitud.

Vemos pues que la interpretación realista de ciertos sueños y otras experiencias extraordinarias hace plausible la idea, ampliamente compartida en el conjunto de todas las culturas, de que las mentes humanas son separables de los cuerpos y que, por tanto, es aceptable creer en la existencia de entidades trascendentes con mente humana. En concreto, los familiares y antepasados fallecidos, que con tanta frecuencia visitan a sus descendientes en los sueños, sobrevivirían de esta manera, como entidades espirituales o almas incorpóreas en un tipo o ámbito diferente de realidad. La distancia conceptual entre el espíritu de un antepasado y un dios antropomórfico es tan pequeña, que no parece desencaminado pensar que entre los habitantes de los panteones tradicionales se cuentan numerosos espíritus divinizados de antepasados ilustres. Muchos cultos africanos a los antepasados parecen corroborar esta suposición.

\footnotetext{
39 Bettie, J. - Middleton, J., Spirit mediumship in Africa, Routledge \& Kegan Paul, London 1968. La generación de dioses familiares en cultos a antepasados en el Oriente Medio Antiguo ha sido exhaustivamente defendida por VAN DER ToOrn, K., Family Religion in Babylonia, Syria and Israel. Continuity and Change in the Forms of Religious Life, E.J. Brill, Leiden - New York - Köln 1996.
} 


\section{Las experiencias extraordinarias en contextos religiosos}

Aunque considero innecesario optar por una definición concreta de "religión", sí creo correcto afirmar que la mayoría de los fenómenos culturales así calificados por el lenguaje corriente comparten tres características que tienen relación con los temas tratados en este escrito: están organizados en torno a la consecución de metas máximamente valiosas (la salvación, la inmortalidad, el nirvana etc.), presuponen la existencia de una realidad trascendente, y utilizan ideas mínimamente anti-intuitivas para representar elementos o aspectos de dicha realidad (dioses, espíritus, vida sin fin, conciencia omnipresente etc.).

En la mayoría de los casos, la consecución de estas metas máximamente valiosas se concibe como un proceso que se extiende a través del tiempo en series o ciclos de prácticas cultuales, ascéticas, morales o espirituales, cuyo fin más inmediato es entrar en contacto con la realidad trascendente. Tales contactos, que en unos casos se establecen a nivel personal y en otros a nivel grupal, pueden tener objetivos muy variados, dependiendo de la tradición religiosa de la que se trate. Pueden servir para congraciarse con el poder incontrolable de lo trascendente, para buscar su protección, renovar la conciencia de su presencia, solicitar y recibir sus favores o para abrirse a la revelación de sus designios.

El hecho de que las experiencias extraordinarias sean un lugar privilegiado de encuentro con formas de alteridad irreducibles a la realidad ordinaria da razón de su relevancia en contextos religiosos. Los datos históricos y etnográficos muestran, en efecto, que la mayor parte de los cultos, movimientos e instituciones religiosas fundamentan aspectos importantes de sus prácticas y creencias apelando a experiencias extraordinarias vividas por sus adeptos, líderes, antepasados o fundadores. Estas experiencias, que llamaremos fundantes, son siempre interpretadas como manifestaciones o revelaciones de entidades trascendentes.

A nivel histórico y antropológico es generalmente difícil, si no imposible, separar lo que una experiencia fundante tuvo de extraordinario y, por tanto, de absolutamente novedoso, de las creencias presupuestas por los sujetos de la misma y por quienes posteriormente la utilizaron para fundar sobre ella un culto, un movimiento o una institución religiosa. Hay muchos casos en los que es difícil saber si la representación de la entidad trascendente que se revela apareció entonces por primera vez, o si era previamente conocida y sólo reveló aspectos novedosos de su ser, poder o voluntad. Lo último es probablemente lo más frecuente, aunque el grado de novedad aportada en cada caso por la revelación puede ser muy varia- 
ble. Así, por ejemplo, el Dios que se manifiesta a Moisés en la zarza se identifica con el dios de Abraham, Isaac y Jacob, pero ahora se revela con la intención novedosa de salvar a su pueblo de la esclavitud (Ex 3,1-10). La figura humana que aparece sentada a la derecha de Dios en la visión de Esteban (Hech 7,56) es seguramente el hijo del hombre revelado a los profetas Ezequiel $($ Ez 1,26) y Daniel (Dn 7,13-14), pero ahora tiene el rostro de Jesús de Nazaret, del crucificado.

En todo lo que sigue denominaré "experiencia religiosa extraordinaria" a una experiencia extraordinaria cuyo sujeto la interpreta en clave religiosa ${ }^{40}$. Evidentemente es posible que el sujeto dé sentido religioso a su experiencia, pero el resto o la mayoría de sus correligionarios rechace esa interpretación. Si él insiste en mantener la suya, la situación puede derivar en distintos tipos de conflictos que se resolverán de un modo u otro según sea la relación de poder entre las partes. Muchos movimientos religiosos nuevos se han originan a partir de situaciones semejantes, cuando el individuo díscolo decide fundar un grupo religioso en el que se acepte el sentido y valor que él otorga a su experiencia.

En un contexto social religioso, los aspectos extraordinarios de una experiencia religiosa extraordinaria dan autoridad a sus contenidos y credibilidad al sujeto de la misma, pues su carácter incontrolable aleja la sospecha de manipulaciones interesadas. Por eso, cuanto más pasivo sea el papel del sujeto en todo el proceso, menos se cuestionará su autenticidad. En estos casos, quienes quieran oponerse al valor religioso de la experiencia sólo podrán aducir que tiene su origen en una enfermedad o en un agente suprahumano maligno, al que posiblemente hay que temer, pero no adorar.

Por otro lado, en la medida en que la interpretación de una experiencia religiosa extraordinaria aceptada como tal por un grupo religioso esté condicionada por creencias previas o sufra elaboraciones orientadas a encajarla en un sistema de pensamiento, su carácter extraordinario quedará consecuentemente mermado. También sufrirá alguna merma si el grupo de creyentes que la valora como fuente de revelaciones o de dones pretende repetirla a voluntad utilizando alguna técnica o instituyendo

\footnotetext{
40 Siguiendo a TAVES, Religious experience, y a RIIS, O. - WoODHEAD, L., A sociology of religious emotion, Oxford University Press, Oxford - New York 2010, considero que las experiencias religiosas extraordinarias, lo mismo que las emociones religiosas, no constituyen un tipo esencialmente distinto de experiencias o de emociones, sino que lo que las caracteriza como "religiosas" es la interpretación que reciben sus contenidos y los contextos sociales en los que se producen.
} 
rituales supuestamente capaces de provocarla. En otras palabras, la institucionalización doctrinal o ritual de las experiencias religiosas extraordinarias se opone a lo que tienen de incontrolable e incomprensible, y por tanto a lo que las hacía precisamente extraordinarias.

Podemos, pues, concluir que, aunque las experiencias extraordinarias ofrecen a las instituciones y movimientos religiosos oportunidades para contactar con la alteridad trascendente, en el momento en que son interpretadas y absorbidas por procesos de institucionalización religiosa pierden necesariamente algo de su carácter extraordinario.

Los procesos de institucionalización religiosa no sólo afectan a la ocurrencia e interpretación de las experiencias extraordinarias, sino también a su relevancia en el conjunto de las creencias y prácticas que definen la vida del grupo creyente. En efecto, cuanto más desarrollados y rígidos sean sus sistemas de prácticas y creencias menos capacidad tendrán para integrar la novedad. Y dado que lo que las experiencias extraordinarias esencialmente aportan es novedad radical, dejarán de ser atractivas para los líderes religiosos. Dichos líderes, cuya función principal en estos grupos es velar por el mantenimiento de la ortodoxia y la ortopraxis, procurarán desincentivar las experiencias extraordinarias desacreditando a los sujetos de las mismas de modo que pierdan credibilidad.

Consiguientemente, las únicas experiencias religiosas extraordinarias que sobreviven en contextos religiosos muy institucionalizadas son aquellas que confirman el correspondiente sistema de prácticas y creencias y que, por tanto, tienen ya muy mermada su capacidad de sorprender. Estas experiencias extraordinarias residuales ocurren, fundamentalmente, en situaciones tipificadas (ritos, ceremonias, prácticas ascéticas o espirituales guiadas etc.) y lo único que suele diferenciarlas de la experiencia religiosa ordinaria es su intensidad emocional.

El papel reducido de las experiencias religiosas extraordinarias en las religiones institucionalizadas contrasta con la importancia que suelen tener en los orígenes de movimientos religiosos nuevos o innovadores ${ }^{41}$. Aunque las peculiaridades de cada movimiento condicionan su relación con lo extraordinario, es posible bosquejar las razones por las que dicha relación existe. En primer lugar, los ambientes sociales y culturales inestables, inseguros, traumáticos o propensos al cambio propician simultáneamente la formación de movimientos nuevos o innovadores a nivel social

\footnotetext{
41 Lewis, Ecstatic religion; Bourguignon, Erika (ed), Religion. Altered states of consciousness and social change, Ohio State University Press, Columbus 1973.
} 
y el incremento de vivencias extraordinarias a nivel personal. En estos ambientes, las experiencias extraordinarias proporcionan ocasiones para descubrir y aceptar novedades capaces de encauzar o dar soluciones nuevas a los problemas sociales, morales o intelectuales que afectan a las personas y a los grupos.

En segundo lugar, la autoridad que en este contexto adquieren los contenidos de las experiencias extraordinarias religiosamente interpretadas favorece la aceptación de novedades tanto a nivel de creencias como de prácticas.

Finalmente, la imposibilidad de limitar las categorías de personas que pueden ser agraciadas con una experiencia extraordinaria, y la autoridad que dichas personas adquieren como representantes o portavoces de lo trascendente, favorece el tipo de cambios en la distribución del poder que caracteriza a los movimientos innovadores. Independientemente del estatus social previo del sujeto, el hecho de tener una experiencia extraordinaria valiosa para el grupo se considera acreditación suficiente para recibir respeto y autoridad.

\section{Conclusión}

La definición de "experiencia extraordinaria" aquí propuesta abarca una gran variedad de experiencias con aspectos o elementos extraordinarios de distintos tipos y grados. Esta definición no es sólo conceptualmente coherente, sino que además tiene un valor heurístico considerable. Permite, en efecto, identificar una serie de fenómenos psicológicos, cognitivos, culturales y religiosos en los que este tipo de experiencias generan consecuencias y dinámicas comparables. Entre dichos fenómenos destacan la búsqueda de técnicas capaces de desencadenar y, en la medida de lo posible, controlar este tipo de experiencias, la creación de nuevos rituales capaces de propiciarlas, la construcción de realidades trascendentes capaces de explicarlas y la elaboración de sistemas religiosos capaces de desarrollar su sentido e integrarlas.

Por otra parte, el hecho de que una experiencia extraordinaria pueda ser más o menos extraordinaria y que su carácter extraordinario pueda sufrir mermas, no sólo no representa dificultad conceptual alguna, sino que nos permite entender las dinámicas de algunos de esos fenómenos. Así, hemos visto cómo el control de la ocurrencia de una experiencia extraordinaria por medio de drogas, técnicas ascéticas o rituales merma su carácter extraordinario, pudiendo convertirse, en el caso extremo de la magia, en una práctica ordinaria de la vida cotidiana del experto. 
La definición de experiencia extraordinaria aquí propuesta también nos ha permitido entender la interpretación que el sujeto o el grupo hacen de la misma como una forma de control cognitivo. Esto, a su vez, nos ha sugerido buscar el origen de algunas representaciones tradicionales mínimamente anti-intuitivas de realidades trascendentes en las experiencias de lo extraordinario.

La posibilidad de concebir un más y un menos en el carácter extraordinario de una experiencia, y de relacionar dicha gradación con el control cognitivo y ritual que los sujetos humanos adquieren sobre ella ha iluminado también la lógica de algunas de las dinámicas que rigen el nacimiento de muchos movimientos religiosos y los procesos de institucionalización religiosa.

Finalmente, la aproximación a la experiencia extraordinaria propuesta en este estudio permite pensar en la capacidad humana para experimentar lo extraordinario, no como una aberración propia de personas ignorantes o una patología mental, sino como una virtud potencial de nuestro sistema cognitivo que facilitaría la asimilación de la novedad en contextos de cambio sociocultural acelerado o de crisis personales. 